\title{
Rectangular Storm Sewer Design Under Equal Sediment Mobility
}

\author{
Jaber Almedeij \\ Department of Civil Engineering, College of Engineering and Petroleum \\ Kuwait University, P.O. Box 5969, Safat 13060, Kuwait
}

Received 2012-03-01; Revised 2012-06-17; Accepted 2012-06-19

\begin{abstract}
Rectangular storm sewers are conduits delivering water to outfall locations and have sizes that are typically larger than standard pipes, by which they become subject to more sediment deposits during operation and thus require higher flow strengths to maintain the bed clean. This study suggests a design procedure of self-cleansing rectangular sewers based on maintaining a lower limit of Shields stress and an upper limit of dimensionless bedload transport capacity. The lower limit of Shields stress is proposed under two considerations: to sustain equal sediment mobility at the channel bottom instead of selective transport and to avoid progressive deposition of finer grains due to low and reducing flows. The upper dimensionless bedload capacity is determined rationally and confirmed by using experimental data obtained from the literature. An existing bedload transport equation developed under equal sediment mobility is modified to provide a basis for the design method. It is shown that the proposed design procedure can practically be applied for a channel to estimate sediment concentrations by setting the required flow strength of Shields tress and particle size. Charts are given as an example for determining explicitly the channel design parameters. The study demonstrates that despite the high flows imposed, the design specifications determined according to this criterion can reasonably be achieved in practice for a given project.
\end{abstract}

Keywords: Outfall locations, sediment mobility, typically larger, sediment particles start, transport capacity, upper dimensionless bedload, experimental data obtained

\section{INTRODUCTION}

Rectangular storm sewers are conduits delivering water to outfall locations and have sizes that are typically larger than standard pipes. The main advantage of designing a sewer with a rectangular cross section is the flexibility of selecting a channel depth and changing the width to acquire larger flows, while in circular sections the sewer size is proportional to the pipe diameter. A common problem in sewer design is to avoid sediment deposition at the bottom of the conduit (Kleijwegt, 1992; Almedeij et al., 2010). This problem has adverse impact on the environment as the sediment can act as pollution store or generator that can be washed out by the first flush into receiving water (Artina et al., 2007; Almedeij et al., 2010; Mannina and Viviani, 2010). The deposits under severe conditions may also cause early water surcharge resulting with a reduction in conduit hydraulic capacity (Ackers, 1991).
The current design practice of rectangular storm sewers is based on the common recommendation of a single minimum water velocity as a generalized rule, which has been found for pipe flows to be inadequate to prevent the accumulation of sediment deposition in the long term (Ackers, 1991; Vongvisessomjai et al., 2010). One essential factor that makes obvious distinction in the design concept between the two sewer types is the shape of the conduit cross section. This factor can affect the assumption of active bed width in generating sediment movement. It is well documented that in pipe flows the effective bed width for sediment transport is a function of water level (Novak and Nalluri, 1975; Ackers, 1984; Delleur, 2001; Gouda et al., 2007). The sediment particles start moving in contact with the bed in a very narrow band, as it tends to concentrate towards the point of maximum depth in the cross section. A larger pipe size becomes subject to sediment deposition more than standard pipes and thus requires a larger slope to achieve 
a higher design velocity (Butler et al., 2003). On the other hand, the effective bed width for sediment transport in rectangular sewers is practically assumed to be the full channel width. This assumption is useful to estimate the capacity of the conduit to transport sediment per unit channel width. That is, a larger sediment transport discharge can be achieved for the design by increasing the width while maintaining the same channel depth and slope. However, a well defined procedure taking into account design factors such as sediment particle size and concentration is necessary for rectangular sewers to maintain self cleansing systems capable of preventing deposition in the long term.

This study suggests a self-cleansing design procedure for rectangular sewers based on sediment transport theory. Initially, the current design practice of self cleansing rectangular sewers will be investigated for a given case study. Then, general assumptions and limitations will be suggested to insure sufficiently high flows capable of transporting sediment. A model based on these considerations will then be developed and discussed.

\subsection{Current Practice}

The current design practice of storm sewer networks can be investigated for Kuwait, which implements more than 290 rectangular conduits draining eventually into the sea. Initially, the design is handled by the Ministry of Public Works, starting with a sewer size of pipe cross section with a diameter as small as $0.25 \mathrm{~m}$. This pipe size is enlarged by the designer as the amount of flowing water accumulates, estimated from the rational equation, until reaching the stage that the largest size employed of $2 \mathrm{~m}$ becomes insufficient. Here, a rectangular sewer with a larger cross section area is employed, which is often variable in size depending on the water flow capacity. The rectangular sewers are made of reinforced concrete cast in place for easy construction. The sewers have different sizes with width to depth ranging from $2 \times 2 \mathrm{~m}$ to $4 \times 2.5 \mathrm{~m}$. Obviously, the minimum size of $2 \times 2 \mathrm{~m}$ is used to give a cross section area larger than that for the 2 $\mathrm{m}$ pipe diameter. On the other hand, a depth ranging from 2-2.5 $\mathrm{m}$ is adopted so that the sewer may have a suitable size for workers to fit inside during maintenance. When the amount of water flowing into the rectangular sewer increases until the largest size becomes unable to absorb it, a multi-cells sewer is used.

The self cleansing design criterion employed for rectangular sewers in Kuwait is based on the common practice recommendation of maintaining a minimum water velocity of $0.75 \mathrm{~m} \mathrm{sec}^{-1}$. This velocity is adopted to reduce sediment deposition at the bottom of the sewer. The design slope must be equal to or greater than that required to maintain this velocity. A limiting velocity of $4.5 \mathrm{~m} \mathrm{sec}$ is also considered to avoid abrasives due to excessive suspended sediment rates on the interior surface of the sewer.

Field observations reported by the Ministry of Public Works indicate considerable sediment deposits mainly inorganic with noncohesive properties of sand size. The thickness of the deposits at some locations is found to be $10 \mathrm{~cm}$, increasing along the conduit to about $50 \mathrm{~cm}$. At the sewer outlet, the thickness of sediment can be even worse due to the high water level variability of sea tides. For some cases, the sewer outlet becomes totally blocked by sediment. The nature of desert climate has also contributed to the problem, since rainfall through the year is infrequent and has short duration. Owing to economical constraints, the Ministry of Public Works conducts a scheduled maintenance for the sewer inlets once a year before the beginning of the rainfall season, while the main conduit is maintained occasionally if blockage or flooding appears.

\subsection{Design Considerations \\ 1.3. General Assumptions and Limitations}

The main assumptions considered here for modeling sediment transport in rectangular storm sewers are channel of steady and uniform gravity system, bed composed of loose and noncohesive sediment and sediment movement under equilibrium condition.

The assumption of steady and uniform gravity system is traditionally considered for simple design of storm sewers under normal flow operations. Regarding the assumption of channel bed composed of loose and noncohesive sediment, conclusions drawn by others report that designing self cleansing storm sewers with loose boundary criteria leads to more economical solutions than that with the limit of deposition especially for large conduits (May, 1993; Ackers et al., 1996; Arthur et al., 1999; and Ota and Nalluri, 2003). This encouraged many researchers to employ field measurements from alluvial channels to model sediment transport in rigid sewers, i.e., transport over permanently deposited sediment bed (Perrusquia, 1991; Nalluri et al., 1994; Ota and Nalluri, 2003). The problem becomes though complicated by the presence of bedforms which play an important role in estimating the overall channel bed roughness. However, if the sewer was designed to operate under sufficiently high shear stresses, then form roughness such as ripples and dunes may be ignored.

The concept of equilibrium sediment transport as proposed by Einstein (1950) is defined as a continual exchange of sediment particles between the water column and the bed surface, by which the same number of a given type and size of particles are deposited on the bed as are entrained from it. This condition allows studying the maximum possible transport rate along the channel bed without tendency for further deposition. 


\subsection{Lower Limit of Shields Stress}

A lower limit of flow strength can be specified for storm sewers under equilibrium condition to ensure more efficient channel capable of entraining sediment particles. The flow strength can be presented in terms of Shields stress parameter $\tau^{*}$ Eq. 1:

$$
\tau^{*}=\frac{\mathrm{RS}}{(\mathrm{G}-1) \mathrm{d}}=\frac{\tau_{\mathrm{o}}}{\left(\gamma_{\mathrm{s}}-\gamma\right) \mathrm{d}}
$$

$\mathrm{S}=$ slope; $\mathrm{R}=$ hydraulic radius; $\mathrm{d}=$ sediment particle size; $\tau_{0}=$ boundary shear stress; $G=$ sediment specific gravity, $G=\gamma_{\mathrm{s}} / \gamma$ equal to 2.65 for sand; $\gamma_{\mathrm{s}}=$ sediment specific weight; and $\gamma=$ water specific weight. Unlike the single minimum water velocity criterion, this parameter takes into account the influence of important sediment and water properties in the design such as the shape of channel cross section, bed slope, size of sediment bed material and submerged weight of sediment. For a channel flow with a hydraulic transition or rough boundary, the smallest $\tau^{*}$ value above which appreciable sediment particles start moving is about 0.03 (Paintal, 1971; Parker, 1979). Consequently, any larger $\tau^{*}$ imposed by the designer in a transporting system provides a flow strength capable of preventing sediment deposition. However, up to some limit, the transport process of sediment is selective, under which bedforms such as ripples and dunes may occur. It is important thus to increase this flow strength by adjusting $\tau^{*}$. This can be handled for two design conditions: for regular design flow and for low or reducing flow.

For regular flow condition, Fig. 1 presents two general cases of bedload transport rates in terms of Eq. 2:

$$
\mathrm{W}^{*}=\frac{(\mathrm{G}-1) \mathrm{q}_{\mathrm{B}}}{\sqrt{\mathrm{g}}(\mathrm{RS})^{1.5}}
$$

where, $\mathrm{W}^{*}=$ dimensionless bedload transport parameter; $\mathrm{q}_{\mathrm{B}}=$ volumetric bedload transport rate per unit channel width; and $g=$ gravitational acceleration. The solid trend depicts the transport behavior for loose boundaries in rectangular channels, while the other one is designated for rigid boundaries in pipe flows at the limit of deposition. The trend of loose boundary channels, which is developed from typical bedload data collected from natural gravel-bed streams under equilibrium or near equilibrium sediment transport and with no bedforms present at the bottom, provides higher bedload transport rates under the same flow conditions. As proposed by May (1993), the reason for the higher transport behavior in loose boundary channels is explained by the presence of the deposited bed material over the full channel width that allows the flow to acquire a greater bedload transport capacity, which can be much greater than the narrow stream of sediment that is present along the bed of the pipe at the limit of deposition.

Despite the differences illustrated in Fig. 1 between a rectangular channel with loose bed material and pipe rigid boundary, the variation of the slope for either trend within the specified range of $\tau^{*}$ suggests the presence of two distinct bedload transport modes, which can be described by using the following relation Eq. 3:

$$
\mathrm{W}^{*}=\alpha \tau^{*} \beta
$$

For $\tau^{*} \leq 0.05$, the slope of the relation is estimated as $\beta \approx 7.95$ and $\approx 8$ for the trend of loose and rigid boundary, respectively. The increasing rate of $\mathrm{W}^{*} \tau^{*}$ values indicates the increasing flow strength capability to selectively transport larger particle sizes from the channel bed, which is the condition of selective transport (Milhous, 1973; Duan and Scott, 2007). As $\tau^{*}$ increases further, larger grains are set in motion until approaching the condition of equal sediment mobility, which is the movement of all particle sizes at rates proportional to their presence in the bed material (Parker et al., 1982). This condition is indicated in the figure by the lower trend slope for nearly $\tau^{*} \geq 0.1$ with $\beta \approx 0.35$ and $\approx 1.56$ for the trend of loose and rigid boundary, respectively.

Field data employed in the development of the trend of loose boundary channels can be used to investigate the variation of bedload material for the two transport modes. The dataset of the perennial Oak Creek, which was originally collected from the field by Milhous (1973) using vortex sampling design, constitutes the lower part of the trend shown in Fig. 1 with the selective transport condition. Oak Creek is about $3.66 \mathrm{~m}$ wide and has bed slope in the range from 0.0083-0.0108 and flow depth 0.11-0.45 m. The bedload material in Oak Creek is dominated by finer grains with median sizes increasing gradually from $0.62-27 \mathrm{~mm}$ that are considerably smaller than the median of the channel surface material, a constant equal to $54 \mathrm{~mm}$. Owing to the lack of field data, Oak Creek cannot be used to prove the possible similarity between the median grain sizes of bedload and surface materials at sufficiently higher flows; however, field observations reported from the ephemeral Nahal Yatir (Reid et al., 1995), the upper part of the trend in Fig. 1, confirms that the median grain sizes of bedload are very close to the median of the surface material, equal to $6 \mathrm{~mm}$. Nahal Yatir, which was sampled automatically using three slot-samplers of the Birkbeck type, is about $3.5 \mathrm{~m}$ wide and has bed slope in the range from 0.007-0.0101 and flow depth $0.1-0.47 \mathrm{~m}$. It is interesting to mention that the stream size and the sampling design for both Oak Creek and 
Nahal Yatir made the datasets unique by measuring bedload across the whole stream width rather than with spot sampling. Although Nahal Yatir has average flow depth and bed slope similar to that of Oak Creek, its median grain size of surface material is smaller by which higher flows prevail $\tau^{*} \geq 0.1$. The implication is that, a lower limit of $\tau^{*}$ equal to 0.1 can be suggested to warrant a more efficient sewer design approaching the condition of equal sediment mobility.

The other issue to consider is the lower limit for low or reducing flows. Whatever velocity or shear stress is specified, at the end of a rainfall event or for rainfall events below the design storm, sediment will deposit on the sewer invert. However, what one needs to avoid is the progressive build-up of sediment deposition in the long term. It is more common that the deposition of finer sediment sizes up to $1 \mathrm{~mm}$ may occur at low and reducing water flows and they become attached to the sewer and to each other during the period before the next major flow. In this case, the deposited material may have cohesive-like properties and would require a higher shear stress to be entrained compared to that necessary for the same size when available in wholly noncohesive condition. Taking account of a review of work by other researchers, Ackers et al. (1996) concluded that based on sediment sizes up to $d=1 \mathrm{~mm}$ a shear stress of $\tau_{0} \sim 2.5$ and $6.7 \mathrm{~N} / \mathrm{m}^{2}$ would be sufficient for the design to erode weak and strong cohesions, respectively. From Eq. 1, the dimensional shear stresses reported have the corresponding $\tau^{*}$ values of $\sim 0.15$ and 0.4 . Accordingly, $\tau^{*}$ may be adjusted for the overall design by increasing its value up to 0.4 in order to provide design flows capable of preventing progressive build-up of finer depositions in the long term due to low or reducing flows.

\subsection{Upper Limit of Bedload Transport}

For considerably high flows, all grain sizes at the bed are rendered of roughly equal mobility and thus a complete similarity between the grain size distribution of bedload and bed material exists. This condition can be satisfied when the slope $\beta$ of Eq. 3 becomes zero and thus $\mathrm{W}^{*}$ is constant. Under these considerations, a stress equilibrium relation can be defined similar to that proposed by Bagnold (1956) such that the applied bed shear stress is equal to the intergranular normal resistance Eq. 4:

$\tau_{\mathrm{o}}=\mathrm{y}_{\mathrm{s}} \gamma(\mathrm{G}-1) \mathrm{C}_{\mathrm{b}} \tan \varphi$

where, $\mathrm{y}_{\mathrm{s}}=$ thickness of bedload layer; $\mathrm{C}_{\mathrm{b}}=$ volumetric sediment concentration within bedload layer; and $\phi=$ angle of repose, $\tan \phi=0.63$ for cohesionless sediment. The condition of equal mobility also makes it possible to assume that the distribution of sediment concentration within the bedload layer is represented by a simple step function within which the particle velocity $u_{s}$ is nearly equal to the water velocity $u$. Accordingly, $\mathrm{q}_{\mathrm{B}}$ can be expressed in the form Eq. 5:

$\mathrm{q}_{\mathrm{B}}=\mathrm{C}_{\mathrm{b}} \mathrm{y}_{\mathrm{s}} \mathrm{u}$

Both Eq. 4 and 5 can be substituted into Eq. 2 resulting with the following dimensionless bedload parameter:

$$
\mathrm{W}^{*}=\frac{\tau_{\mathrm{o}} \mathrm{u}}{\gamma \sqrt{\mathrm{g}}(\mathrm{RS})^{1.5} \tan \varphi}
$$

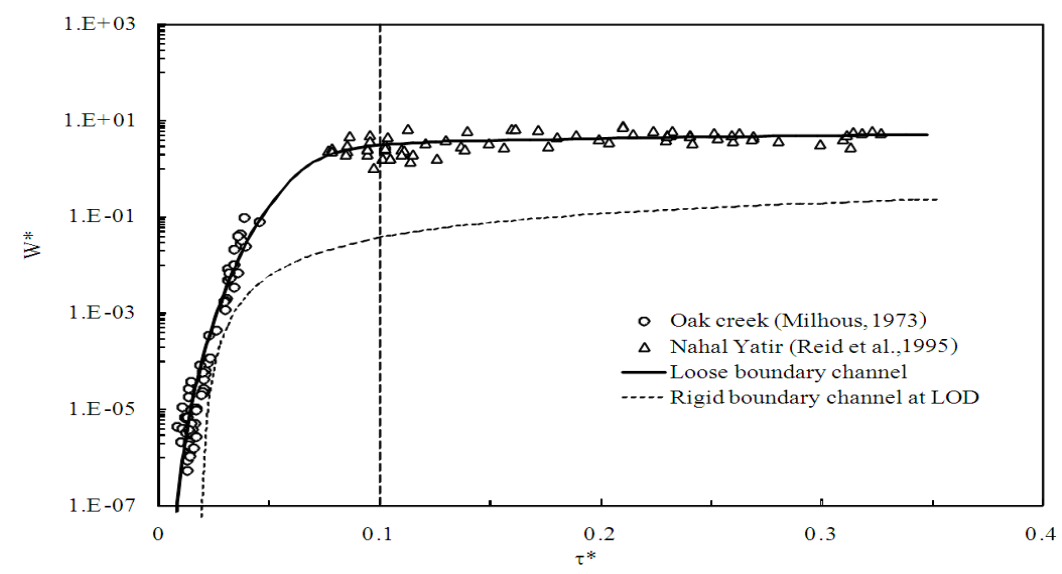

Fig. 1. Average relation of bedload transport rates within a wide range of Shields stresses. The solid-line relation was plotted for gravel-bed streams using Almedeij and Diplas (2003) and the dash-line for pipes at the limit of deposition (LOD) using May [Ackers et al. (1996)]. The relation of May is based on sediment particle $\mathrm{d}=0.75 \mathrm{~mm}$, pipe size $\mathrm{D}=0.5 \mathrm{~m}$ and pipe roughness $\mathrm{k}_{0}=0.6 \mathrm{~mm}$ 
The logarithmic law can be used to estimate $u$ near the bed under hydraulically rough boundary Eq. 7:

$\frac{\mathrm{u}}{\mathrm{u}_{*}}=\left.\frac{1}{\mathrm{k}} \ln \left(30.2 \frac{\mathrm{z}}{\mathrm{d}}\right)\right|_{\mathrm{z}=\mathrm{d} / 2}$

where, $\mathrm{k} \approx 0.4$ Karman's constant for clear water; $\mathrm{u}_{*}=$ shear velocity, $\mathrm{u}_{*}=\sqrt{\tau_{0} / \rho}$; and $\mathrm{z}=$ depth from zero velocity, $\mathrm{z}=\mathrm{d} / 2$ assuming a spherical particle. Solving the above equation yields:

$u=6.79 \sqrt{\frac{\tau_{0}}{\rho}}$

Equation 8 can be substituted into Eq. 6 resulting with:

$\mathrm{W}^{*} \approx 10.8$

This value suggests that the bedload transport process approaches an upper limit capacity at equilibrium stresses when the condition of equal sediment mobility dominates.

To this extent, Eq. 9 is rational rather than empirical. It is interesting to confirm this upper capacity by using bedload data obtained from sufficiently high flows. The bedload data of Nahal Yatir can be tested. As it was mentioned earlier, Nahal Yatir operates under high flows approaching the condition of equal sediment mobility $\tau^{*} \geq 0.1$. The fitting coefficients of Eq. 3 can be obtained for Nahal Yatir by means of log-linear regression as Eq. 10:

$\mathrm{W}^{*}=7.57 \tau^{* 0.35}$

which is very close but not sufficient to confirm the upper capacity of bedload.

Another bedload data of Nnadi and Wilson (1992) operating under higher flows than Nahal Yatir will be particularly useful. The Nnadi and Wilson experiments were conducted in a pressurized horizontal conduit with no bedforms present at the channel bottom, composed of sand with $G=2.67$ and $d=0.7 \mathrm{~mm}$. The conduit has a square cross section of $98 \times 98 \mathrm{~mm}$ and the range of flows considered is $0.8 \leq \tau^{*} \leq 8$. As it was proposed by them, there are two main advantages of employing the pressurized conduit over traditional flume studies. The first one is introducing high shear stresses by adjusting the slope for the energy grade line rather than the bed for a relatively small water depth without imposing a significant component of particle submerged weight in the direction of flow as the bed of the channel can be horizontal. The second advantage is eliminating the possible interaction of water free surface on channel bed configuration, thus decoupling antidunes typically found at Froude numbers somewhat greater than unity. As shown in Fig. 2, the average trend exhibited by the bedload data of Nnadi and Wilson is well represented by Eq. 11.

\subsection{Model Development}

A bedload equation suitable for $\tau^{*} \geq 0.1$ can form the basis of a design criterion for self cleansing rectangular sewers. The data of Nahal Yatir and of Nandi and Wilson will be used to test selected models shown in Table (1). Those models were chosen here because they have been widely applied in the literature for high bedload transport rates with loose boundary channels and the parameter $\mathrm{W}^{*}$ turns into a constant for $\tau^{*} \gg \tau_{\mathrm{c}}^{*}$. Figure 3 shows that under high flows the bedload equations display nearly similar asymptotic behavior. Of particularly interest is the model of Parker (1979), fitted using 278 bedload datasets from gravel streams. This model apparently fits the average of the two datasets better than the others and renders $\mathrm{W}^{*}$ for sufficiently high flows equal to 11.2 , which is very close to 10.8 . It is worth mentioning that Parker et al. (1982) adopted this model to estimate the bedload transport rates for upper flows under which the condition of equal mobility dominates.

A comparison for the accuracy of the models can be performed in an objective manner. Owing to the reason that the data in the figure are presented in a logarithmic scale, an equation based on the Mean Absolute Standard Error (MASE) becomes suitable for this analysis:

MASE $=\frac{\sum_{\mathrm{i}=1}^{\mathrm{j}} \mathrm{W}_{\mathrm{ri}}^{*}}{\mathrm{n}}$

Where:

$\mathrm{W}_{\mathrm{ri}}^{*}=\left\{\begin{array}{l}\frac{\mathrm{W}_{\mathrm{i} \text { observed }}^{*}}{\mathrm{~W}_{\mathrm{i} \text { calculated }}^{*}} \text { if } \mathrm{W}_{\mathrm{i} \text { observed }}^{*}>\mathrm{W}_{\mathrm{i} \text { calculated }}^{*} \\ \frac{\mathrm{W}_{\mathrm{i} \text { observed }}^{*}}{\mathrm{~W}_{\mathrm{i} \text { calculated }}^{*}} \text { if } \mathrm{W}_{\mathrm{i} \text { observed }}^{*}<\mathrm{W}_{\mathrm{i} \text { calculated }}^{*}\end{array}\right.$

Equation 13 indicates that MASE $\geq 1$. The closer the MASE value to one, the better is the accuracy of an equation, with MASE $=1$ representing the condition of perfect agreement. The error by this equation is standardized to render a calculated value of, e.g., 0.02 or 20 compared to a corresponding measurement of 0.01 or 10 equivalent, i.e., MASE $=2$. As can be seen in Table 1, the calculated errors by this criterion confirm the better performance of Parker's model.

Figure 3 also shows an adjusted model for Parker based on the proposed upper bedload capacity (Eq. 9) resulting with the form:

$$
\mathrm{W}^{*}=10.8 \frac{\left(\tau^{*}-0.03\right)^{4.5}}{\tau^{* .5}}
$$


Jaber Almedeij / American Journal of Environmental Science 8 (4) (2012) 376-384

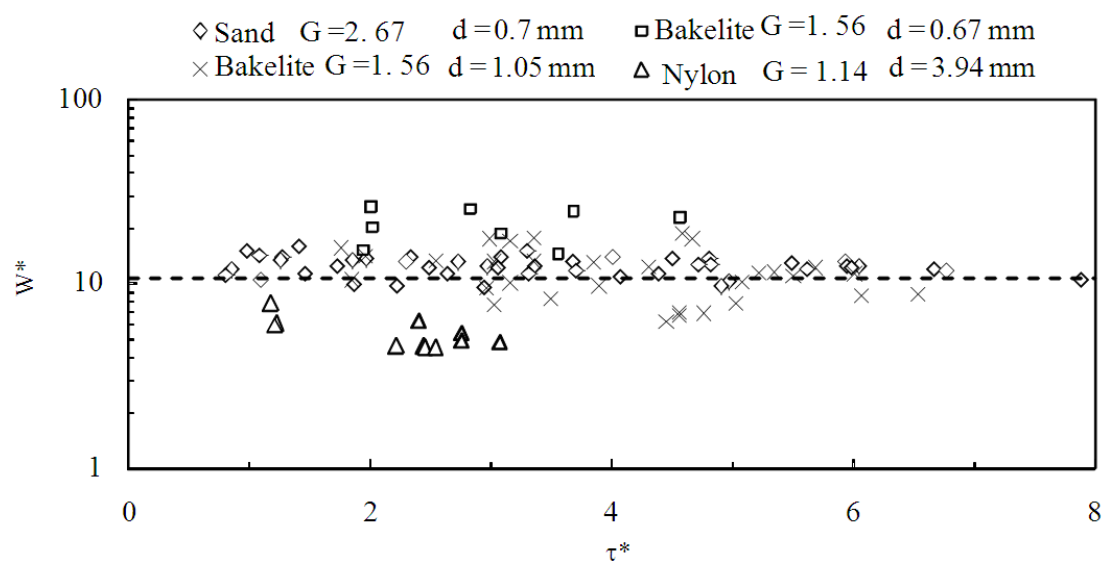

Fig. 2. Bedload data of Nnadi and Wilson with the dash-line representing $\mathrm{W}^{*}=10.8$

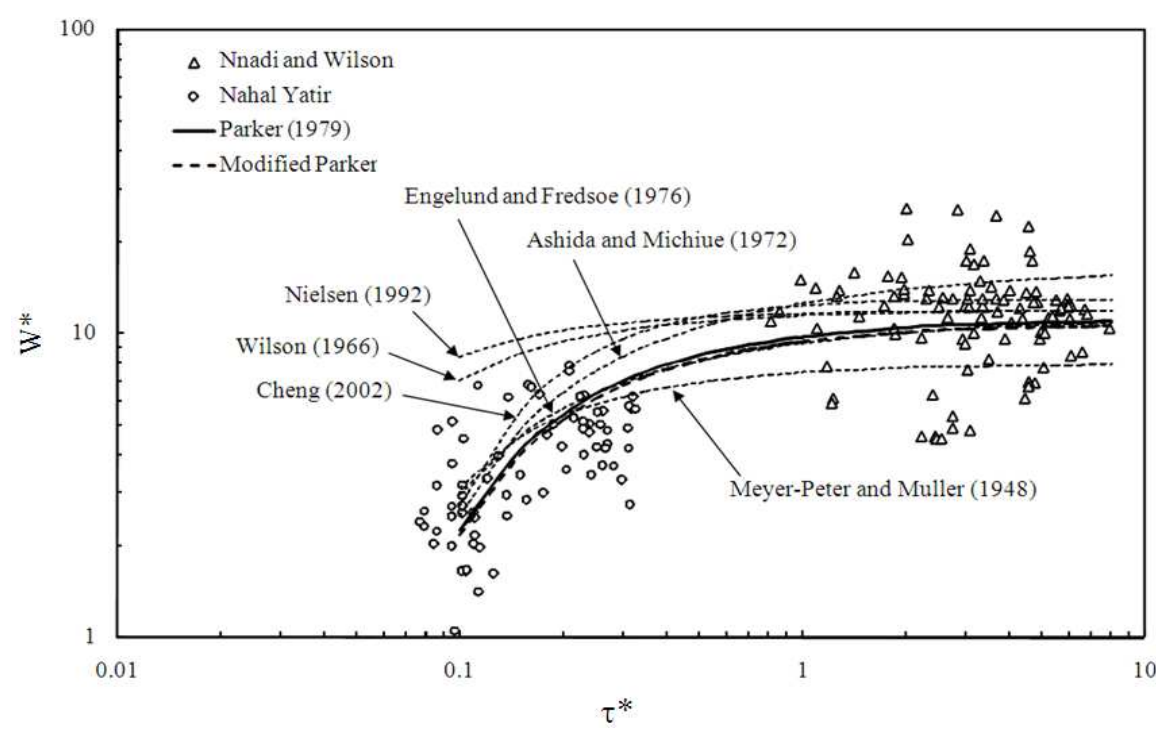

Fig. 3. Comparison of selected bedload equations fitted against the bedload data of Nahal Yatir (Reid et al. 1995) and of Nnadi and Wilson (1992)

Table 1. Selected bedload equations and their fitting accuracy against the data of Nahal Yatir (Reid et al. 1995) and of Nnadi and Wilson (1992)

\begin{tabular}{lllll}
\hline Reference & Equation & $\tau_{\mathrm{c}}^{*}$ & $\mathrm{~W}^{*}$ for $\tau^{*}>>\tau_{\mathrm{c}}^{*}$ & MASE \\
\hline Meyer-Peter and Muller (1948) & $\mathrm{W}^{*}=8\left(\tau^{*}-\tau_{\mathrm{c}}^{*}\right)^{1.5} / \tau^{* 1.5}$ & 0.047 & $\mathrm{~W}^{*} \approx 8$ & 1.56 \\
Wilson (1966) & $\mathrm{W}^{*}=12\left(\tau^{*}-\tau_{\mathrm{c}}^{*}\right)^{1.5} / \tau^{* 1.5}$ & 0.030 & $\mathrm{~W}^{*} \approx 12$ & 1.80 \\
Ashida and Michiue (1972) & $\mathrm{W}^{*}=17\left(\tau^{* 0.5}-\tau_{\mathrm{c}}^{* 0.5}\right) / \tau^{* 1.5}$ & 0.050 & $\mathrm{~W}^{*} \approx 17$ & 1.52 \\
Engelund and Fredsoe (1976) & $\mathrm{W}^{*}=11.6\left(\tau^{*}-\tau_{\mathrm{c}}^{*}\right)\left(\sqrt{\left.\tau^{*}-0.7 \sqrt{\tau_{\mathrm{c}}^{*}}\right) / \tau^{* 1.5}}\right.$ & 0.050 & $\mathrm{~W}^{*} \approx 16.7$ & 1.43 \\
Parker (1979) & $\mathrm{W}^{*}=11.2\left(\tau^{*}-\tau_{\mathrm{c}}^{*}\right)^{4.5} / \tau^{* 4.5}$ & 0.030 & $\mathrm{~W}^{*} \approx 11.2$ & 1.40 \\
Nielsen (1992) & $\mathrm{W}^{*}=12 \tau^{* 0.5}\left(\tau^{*}-\tau_{\mathrm{c}}^{*}\right) / \tau^{* 1.5}$ & 0.050 & $\mathrm{~W}^{*} \approx 12$ & 1.92 \\
Cheng (2002) & $\mathrm{W}^{*}=13 \tau^{* 1.5} \exp \left(-\tau_{\mathrm{c}}^{*} / \tau^{* 1.5}\right) / \tau^{* 1.5}$ & 0.050 & $\mathrm{~W}^{*} \approx 13$ & 1.52 \\
\hline
\end{tabular}




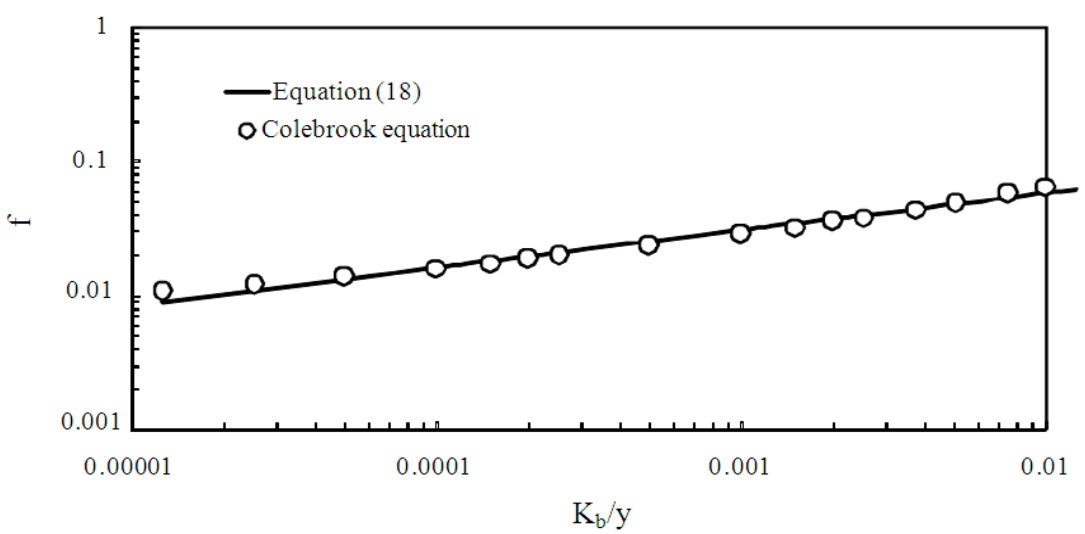

Fig. 4. Friction factor estimated from a simplified Colebrook equation (Eq. 17). The trend was fitted by using log-linear regression

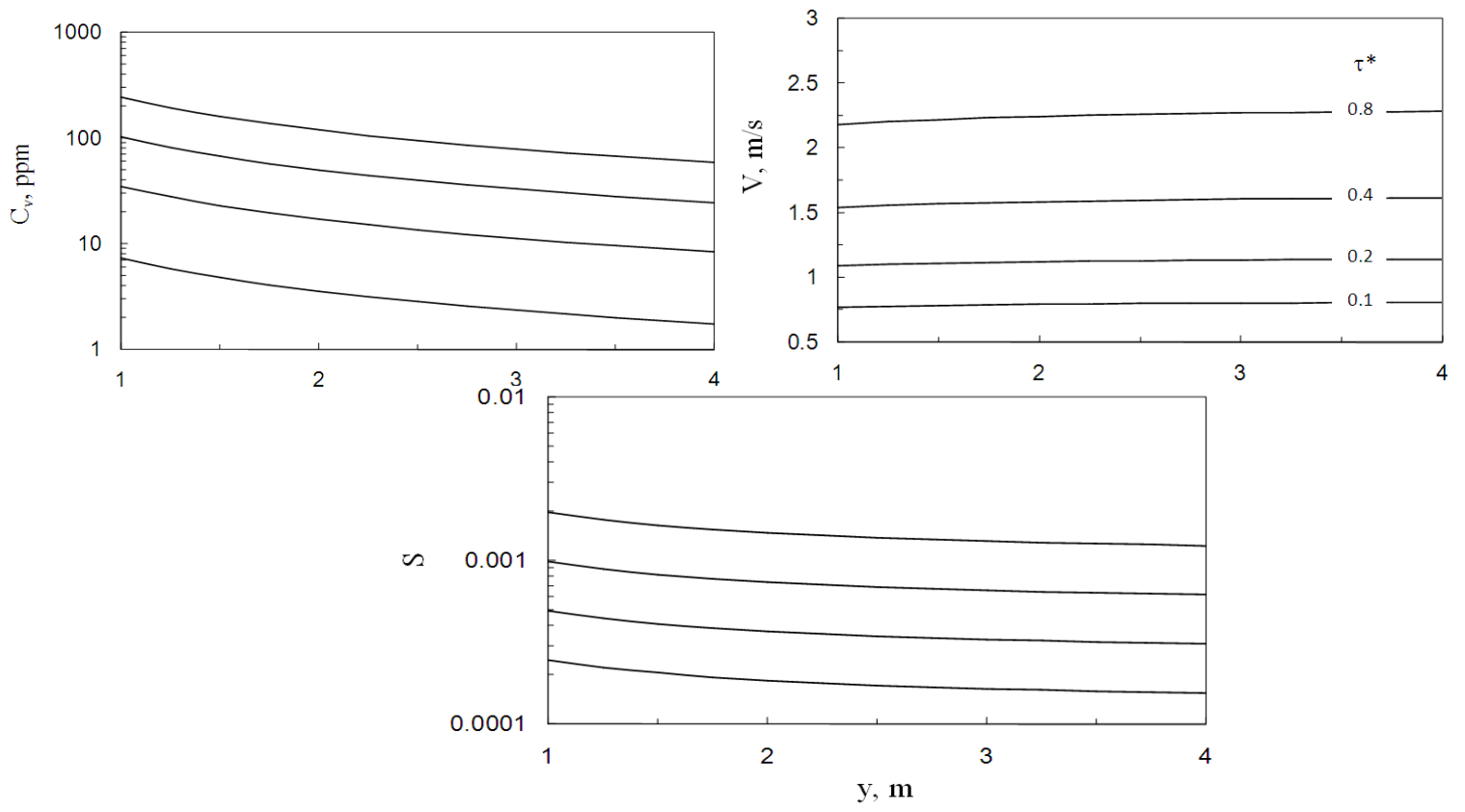

Fig. 5. Self cleansing design criterion for a size range of rectangular sewers with $b=2 \mathrm{~m}, \mathrm{~d}=0.75 \mathrm{~mm}$ and $\mathrm{G}=2.65$

The fitting accuracy has been slightly improved compared to the original model of Parker, where MASE became 1.38. From Eq. 2 and given $\mathrm{q}_{\mathrm{B}}$ in terms of volumetric sediment concentration $\mathrm{C}_{\mathrm{v}}$, water depth $\mathrm{y}$ and average water velocity $\mathrm{v}$ Eq. 13:

$$
\mathrm{q}_{\mathrm{B}}=\mathrm{C}_{\mathrm{v}} \mathrm{yV}
$$

Equation 12 can be rewritten as Eq. 14:

$$
\mathrm{C}_{\mathrm{v}}=\frac{\sqrt{\mathrm{g}}(\mathrm{RS})^{1.5}}{\mathrm{~V}(\mathrm{G}-1) \mathrm{y}}\left[10.8 \frac{\left(\tau^{*}-0.03\right)^{4.5}}{\tau^{* 4.5}}\right]
$$

For the above relation, $\mathrm{v}$ can be estimated from the Darcy-Weisbach Eq. 15:

$$
V=\sqrt{\frac{8 R S g}{f}}
$$

where, $\mathrm{f}=$ friction factor, which can be determined from the Colebrook Eq. 16:

$$
f=\left\{\frac{1}{-0.86 \ln \left[\frac{k_{b}}{3.7(4 R)}+\frac{2.51}{\operatorname{Re} \sqrt{f}}\right]}\right\}^{2}
$$


$\mathrm{k}_{\mathrm{b}}=$ bed roughness; and $\mathrm{Re}=$ Reynolds number. Equation 18 can be simplified for sufficiently large Re as:

$$
\mathrm{f}=\left\{\frac{1}{-0.86 \ln \left[\frac{\mathrm{k}_{\mathrm{b}}}{3.7(4 \mathrm{R})}\right]}\right\}^{2}
$$

Further simplification can even be achieved by using this shorter expression of Colebrook equation to plot the data points shown in Fig. 4 and then fitting the following log-linear relation:

$$
f=0.06\left(\frac{k_{b}}{R}\right)^{0.2}
$$

Substituting Eq. 1, 15 and 18 into Eq. 14 yields:

$$
C_{v}=0.935\left(\frac{k_{b}^{0.1} d}{R^{0.1} y}\right) \frac{\left(\tau^{*}-0.03\right)^{4.5}}{\tau^{* 3.5}}
$$

The difficulty here is in estimating accurately the bed roughness $\mathrm{k}_{\mathrm{b}}$. However, the 0.1 exponent on this parameter suggests a relatively small dependency with $\mathrm{C}_{\mathrm{v}}$. Accordingly, for a loose channel bed with relatively high Shields stresses where bedforms such as ripples and dunes may be ignored, it can be assumed that $\mathrm{k}_{\mathrm{b}}^{0.1} \mathrm{~d} \approx \mathrm{d}^{1.1}$. That is, if $\mathrm{k}_{\mathrm{b}}=\mathrm{d}$, then $\mathrm{k}_{\mathrm{b}}^{0.1} \mathrm{~d}=\mathrm{d}^{1.1}$; if $\mathrm{k}_{\mathrm{b}}=2 \mathrm{~d}$, then $\mathrm{k}_{\mathrm{b}}^{0.1} \mathrm{~d}=1.07 \mathrm{~d}^{1.1}$; if $\mathrm{k}_{\mathrm{b}}=3 \mathrm{~d}$, then $\mathrm{k}_{\mathrm{b}}^{0.1} \mathrm{~d}=1.116 \mathrm{~d}^{1.1}$; and so forth. Eq. 19 can thus be written such that Eq. 20:

$$
C_{v}=0.935\left(\frac{d^{1.1}}{R^{0.1} y}\right) \frac{\left(\tau^{*}-0.03\right)^{4.5}}{\tau^{* 3.5}}
$$

Although the 0.1 exponent on $\mathrm{R}$ can also suggest a relatively small dependency with $\mathrm{C}_{\mathrm{v}}$, further simplification of the above equation by assuming $\mathrm{R}^{0.1} \mathrm{y} \approx$ $\mathrm{y}^{1.1}$ is not necessary. The reason is that $\mathrm{R}$ can explicitly be specified for a given design project, unlike $k_{b}$ which imposes estimation uncertainties. Furthermore, the error resulted from the assumption $\mathrm{R}^{0.1} \mathrm{y} \approx \mathrm{y}^{1.1}$ is less than 1.0 as long as $b>y$. This is evident given that Eq. 21:

$$
R^{0.1} y=\left(\frac{y b}{2 y+b}\right)^{0.1} y=\frac{b^{0.1}}{(2 y+b)^{0.1}} y^{1.1}
$$

That is, if $\mathrm{b}=\mathrm{y}$, then $\mathrm{R}^{0.1}=0.89 \mathrm{y}^{1.1}$; if $\mathrm{b}=2 \mathrm{y}$, then $\mathrm{R}^{0.1} \mathrm{y}=0.933 \mathrm{y}^{1.1}$; if $\mathrm{b}=3 \mathrm{y}$, then $\mathrm{R}^{0.1} \mathrm{y}=0.95 \mathrm{y}^{1.1}$ and so forth. Because $\mathrm{R}^{0.1} \mathrm{y}$ is located in the denominator, the error will be amplified by that resulted from the assumption $\mathrm{k}_{\mathrm{b}}^{0.1} \mathrm{~d} \approx \mathrm{d}^{1.1}$.
Equation 20 can be applied by setting $\tau^{*}$ and $d$ values for a given channel size to estimate $\mathrm{C}_{\mathrm{v}}$. Figure 5 presents a design example for a channel width $b=2 \mathrm{~m}$ to determine explicitly the slope $\mathrm{S}$, velocity $\mathrm{V}$ and sediment concentration $\mathrm{C}_{\mathrm{v}}$. In this figure, $\mathrm{S}$ is estimated from Eq. 1, v from Eq. 15 and $C_{v}$ from Eq. 20. The flow strengths are plotted in the range from $\tau^{*}=0.1-0.8$. Apparently, the determined design slopes are not very steep and can possibly be achieved for a given land surface. The velocities are also acceptable within $0.75 \mathrm{~m} \mathrm{~s}^{-1}$ and 2.3 $\mathrm{m} \mathrm{s}^{-1}$, which are less than the limiting value $4.5 \mathrm{~m} \mathrm{sec}$. Regarding the sediment concentration values, they vary widely for the specified conditions from $1.7-250 \mathrm{ppm}$. Nevertheless, the figure can be used to understand the response of the selected design for the possible imbalance experienced in field between sediment supply and transport. That is, if sediment supply is higher than that under which the sewer is intended to carry during the design flow, deposition may occur on the bottom. If a lower sediment supply is received, the sewer would be able to carry the load as well as part of the material deposited previously on the bottom until approaching the transport capacity under which the sewer was designed. One may deduce that a selected design strength will not be sufficient to avoid deposition once the sewer becomes a subject to higher sediment supplies.

\section{CONCLUSION}

This study suggested a design criterion for self cleansing rectangular sewers based on maintaining a lower limit of Shields stress and an upper limit of dimensionless bedload transport capacity. The lower limit has been proposed as $\tau^{*}=0.1$ for regular flows. This value can be adjusted further up to $\tau^{*}=0.4$ as an attempt to prevent progressive build-up of finer sediment deposition in the long term due to low or reducing water flows. The upper limit of bedload transport capacity has been proposed as $\mathrm{W}^{*} \approx 10.8$. It has been shown that this value is in agreement with the average trend exhibited by the experiments of Nnadi and Wilson. The value has been used to adjust the bedload equation of Parker (1979) as an attempt to model sediment concentration in rectangular sewers. Charts were given in Fig. 5 as an example for determining the design parameters explicitly. This example shows that the determined design slopes are not very steep and can possibly be achieved for a given land surface.

\section{REFERENCES}

Ackers, J.C., D. Butler and R.W.P. May, 1996. Design of Sewers to Control Sediment Problems. 1st Edn., CIRIA, London, ISBN-10: 0860174433, pp: 181. 
Ackers, P., 1984. Sediment transport in sewers and design implications. Proceedings of the International Conference on the Planning, Construction, Maintenance and Operation of Sewerage Systems, (PSS' 84), The University of Reading, England, pp: 825-825.

Ackers, P., 1991. Sediment aspects of drainage and outfall design. Proceedings of the International Symposium Environmental Hydraulics, (EH' 91), Hong Kong, Balkema, Rotterdam.

Almedeij, J. and P. Diplas, 2003. Bedload transport in gravel-bed streams with unimodal sediment. J. Hydraulic Eng., 129: 896-904. DOI: 10.1061/(ASCE)0733-9429(2003)129:11(896)

Almedeij, J., E. Ahmad and J. Alhumoud, 2010. Representative particle size of sediment in storm sewer inlets. Am. J. Environ. Sci., 6: 316-323. DOI:10.3844/ajessp.2010.316.323

Arthur, S., R.M. Ashley, S. Tait and C. Nalluri, 1999. Sediment transport in sewers: A step towards the design of sewers to control sediment problems. Proc. Instit. Civil Eng. Water Maritime Energy, 136: 9-19. DOI: 10.1680/iwtme.1999.31264

Artina, S., A. Bolognesi, T. Liserra and A. Maglionico, 2007. Simulation of a storm sewer network in industrial area: comparison between models calibrated through experimental data. Environ. Mod. Software, 22: 12211228. DOI: 10.1016/j.envsoft.2006.11.002

Ashida, K. and M. Michiue, 1972. Study on hydraulic resistance and bed-load transport rate in alluvial streams. Trans. Japan Soc. Civil Eng., 206: 59-69.

Bagnold, R.A., 1956. The flow of cohesionless grains in fluids. Philosophical Trans. Royal Soc. London, 249: 235-297. DOI: 10.1098/rsta.1956.0020

Butler, D., R. May and J. Ackers, 2003. Self-cleansing sewer design based on sediment transport principles. J. Hydraulic Eng., 129: 276-283. DOI: 10.1061/(ASCE)0733-9429(2003)129:4(276)

Cheng, N.S., 2002. Exponential formula for bedload transport. J. Hydraulic Eng., 128: 942-946. DOI; 10.1061/(ASCE)0733-9429(2002)128:10(942)

Delleur, J.W., 2001. New results and research needs on sediment movement in urban drainage. J. Water Res. Plann. Manag., 127: 186-193. DOI: 10.1061/(ASCE)0733-9496(2001)127:3(186)

Duan, J.G. and S. Scott, 2007. Selective bed-load transport in Las Vegas Wash, a gravel-bed stream. J. Hydrol., 342: 320-330. DOI: 10.1016/j.jhydrol.2007.06.001

Einstein, H.A., 1950. The bed-load function for sediment transportation in open channel flows. U.S. Government Printing Office.

Engelund, F. and J. Fredsoe, 1976. A sediment transport model for straight alluvial channels. Nordic Hydrol., 7: 293-306.
Gouda, H., R. Ashley, J. Blanksby and A. Adams, 2007. Sewer sediment management and hydraulic modeling. Wastewater Planning Users Group Conference, Coventry, UK.

Kleijwegt, R.A., 1992. On Sediment Transport in Circular Sewers with Non-Cohesive Deposits. Ph.D. Thesis, Delft University of Technology.

Mannina, G. and G. Viviani, 2010. An urban drainage stormwater quality model: Model development and uncertainty quantification. J. Hydrol., 381: 248-265. DOI: 10.1016/j.jhydrol.2009.11.047

May, R.W.P., 1993. Sediment Transport in Pipes and Sewers with Deposited Beds. HR Wallingford Limited (Wallingford), London, pp: 100.

Meyer-Peter, E. and R. Muller, 1948. Formulas for bedload transport. IAHR.

Milhous, R.T., 1973. Sediment Transport in a GravelBottomed Stream. Ph.D. Thesis, Oregon State University, Corvallis.

Nalluri, C., A.A. Ghani and A. El-Zaemey, 1994. Sediment transport over deposited beds in sewers. Water Sci. Technol., 29: 125-133.

Nielsen, P., 1992. Coastal bottom boundary layers and sediment transport. 1st Edn., World Scientific, River Edge, N.J. ISBN-10: 9810204736 , pp: 324

Nnadi, F.N. and K.C. Wilson, 1992. Motion of contactload particles at high shear stress. J. Hydraulic Eng., 118: 1670-1684. DOI: 10.1061/(ASCE)07339429(1992)118:12(1670)

Novak, P. and C. Nalluri, 1975. Sediment transport in smooth fixed bed channels. J. Hydraulics Division, 101: 1139-1154. Ota, J.J. and C. Nalluri, 2003. Urban storm sewer design: Approach in consideration of sediments. J. Hydraulic Eng., 129: 291-297. DOI: 10.1061/(ASCE)0733-9429(2003)129:4(291)

Paintal, A.S., 1971. Concept of critical shear stress in loose boundary open channels. J. Hydraulic Res., 9: 91-113.

Parker, G., 1979. Hydraulic geometry of active gravel rivers. J. Hydraulics Division, 105: 1185-1201. Parker, G., P.C. Klingeman and D.G. McLean, 1982. Bedload and size distribution in paved gravel-bed streams. J. Hydraulics Division, 108: 544-569.

Perrusquia, G., 1991. Bedload Transport in Storm Sewers: Stream Traction in Pipe Channels. Ph.D. Thesis, Chalmers University of Technology, Sweden.

Reid, I., J.B. Laronne and D.M. Powell, 1995. The Nahal Yatir bedload database: Sediment dynamics in a gravelbed ephemeral stream. Earth Surface Proce. Landforms, 20: 845-857. DOI: 10.1002/esp.3290200910

Vongvisessomjai, N., T. Tingsanchali and M.S. Babel, 2010. Non-deposition design criteria for sewers with part-full flow. Urban Water J., 7: 61-77. DOI: $10.1080 / 15730620903242824$

Wilson, J.T., 1966. Did the atlantic close and then reopen? Nature, 211: 676-681. DOI:10.1038/211676a0 